It is difficult to speak too highly of Martindale as a source of information on drugs and medicines. Most pharmacists would not feel that their equipment was complete without the latest edition of Martindale, and it would represent a responsible attitude on the part of all prescribing doctors if they ensured that they had ready access to it, for the frequent questions that arise in day-to-day patient care. At almost any price it would be value for money, and this edition will prove a first-class investment for individuals as well as institutional and departmental libraries. Finally, it should be noted that this new edition is available online throughout the world.

PAUL TURNER,

St Bartholomew's Hospital, London EClA 7BE.

\section{Practical Gastrointestinal Endoscopy}

By Peter B. Cotton and Christopher B. Williams. 2nd edn. Pp. xi +204 , illustrated. Blackwell Scientific Publications, Oxford, London, Edinburgh, Boston, Melbourne, 1982. $£ 16.50$.

The second edition of this book has appeared only 3 years after the first. A new medical book must always be a gamble, but a publisher is only likely to launch a second edition if he is sure of his ground. We can therefore take it that this little book has proved to be a success, and that the second edition will be even better-and so it is. In the words of the authors 'this book is concerned with endoscopic techniques and says little about their clinical relevance' and therefore there are the expected chapters, for example Upper Gastrointestinal Endoscopy, Duodenoscopic Sphincterotomy, Colonoscopic Polypectomy. However, endoscopy cannot be practised well without a reliable organization to back the endoscopist. In this context, there are, for example, chapters entitled The Endoscopy Unit, The Endoscopy Nurse/Assistant, and Infection, Cleaning and Disinfection.

The line drawings are excellent, the radiographs well chosen, the colour plates perhaps superfluous; the layout is rational, the style lucid, and the book is a pleasure to hold and to use. It does not set out to list or discuss the place of endoscopy in clinical practice, but the authors should be congratulated on achieving their stated objectives. The book has no serious rival, and as it is cheap, there can be no excuse for not buying it. Every Endoscopy Unit must have a copy, and every endoscopist and every endoscopy nurse, however experienced, should read it.

\section{K. F. R. SCHILLER,} Department of Gastroenterology, St. Peter's Hospital, Chertsey, Surrey.

\section{A Synopsis of Psychiatry}

By John Harding Price. Pp. xi +493, illustrated. Wright PSG, Bristol, London, Boston, 1982. $£ 15.00$

I have to say that I found this a very disappointing book. Page after page was unrelentingly accompanied by what I consider to be errors and inadequacies. It is strongest on electroencephalography, and there are numerous illustrations of EEGs, but one must recognize that the EEG's contribution to routine clinical psychiatry is modest.

The space devoted to the clinical description of the depressed patient was only a sixth of that given over to the formulae of antidepressant drugs. The reader is led to believe that endogenous depression is always a psychotic illness in which the patient is always out of touch with reality and usually delyded. There was no recognition that like everything else about the central nervous system there is an unlimited range of intensities of depressive illness and that many depressed patients, especially those that have had the illness before, are fully in touch with reality. The reader of this book would not realize that depressed patients often present with complaints of bodily dysfunction, nor that many patients fail to respond to antidepressants.
}

The section on the Special Hospitals revealed a lack of experierce of the practical problems of psychiatry in those hospitals; squeeze technique for premature ejaculation was misunderstoed; reference made to cataplexy was not accompanied by any mention of its provocation by emotions, such as laughter; insomnia was to treated by 'relief of id drives'. Contrary to the author, benzodiazepines are useless for the management of aggressive persona disorders. The passage on the aetiology of epilepsy mentioned dregs and alcohol, but did not help the reader to understand that i

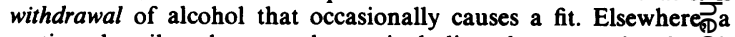
section describes drug psychoses, including those associated with amphetamine, and then 'drug withdrawal syndrome' is describeçs if all drug withdrawal syndromes were the same, whereas in reality the author was describing the picture as of barbiturate withdrawapa picture having no similarity with the anergic, sleepy, patient whose amphetamine has ceased. It all depends on the drug.

I cannot recommend that this book should be bought.

IAN OSWALDC University of Edinburgh Medical School,, 3 Edinburgh EH8 9AG:

Textbook of Orthopaedic Medicine. Vol. 1: Diagnosis of Soft Tisstü Lesions

By James Cyriax. 8th edn. Pp. xi +502 , illustrated. Baillie Tindall, London, 1983. £21.00.

Dr Cyriax has devoted his life to devising a system of diagnosis a fid treatment for the soft tissue, periarticular disorders. His contribution has been enormous. The continuing popularity of his reguffr courses, as well as his many books, is evidence of the importaper of these painful conditions, and the inadequate time and space alfitid to them in other teaching. How many of us, for example, have taught how to detect and treat infraspinatus tendinitis in mical school or on postgraduate courses? How many of us even where it is?

Unfortunately, Dr Cyriax does not do himself justice in this boof It is an extraordinary mixture of the sublime and ridiculous.

On the positive side, the book provides a good description of moss of the periarticular disorders, and outlines their diagnosis by hist\&y and examination. The division of these painful lesions into these detected on passive movement and those exacerbated by resised active movement is an example of the author's logical and help approach. His constant reminder that it is often misleading palpate for tenderness at the area outlined by the patient containsa message for us all.

There is much on the negative side as well. The style is both pedantic and pompous, I found the organization of the chapters and subheadings strange and confusing, and the book is too long. Ma references are included, some of them are up to date, but the choize of data quoted seems strange and haphazard and much of the commenting on the understanding of rheumatic disorders is sady out of date. Although the emphasis of the book is on diagnosis. $\overrightarrow{\mathrm{Dr}}$ Cyriax has a good deal to say about therapy as well. Many of his suggestions would be disputed by orthopaedic surgeons and rheume tologists. Some seem dangerous, for example, phenylbutazone widely recommended without mention of its dangers, and pol myalgia rheumatica is dismissed as being non-existent.

If this book was condensed, and if it kept to the subject of its title it could be a masterpiece. Sadly it isn't, and the excursions into tof aetiology, pathogenesis and therapy of orthopaedic and rheumatio disorders are confusing and often inaccurate. However, if you afe able to extract the wisdom and logic of the system of diagnosis without believing the theory then the book could be very usefulco P. A. DIEPPE, $\frac{\varsigma}{\Phi}$ Bristol Royal Infirmary, Bristol BS2 8HW. 